STRESS induces chemical changes in the central nervous system which alters the biochemistry and physiology of the digestive tract. The present study determines arachidonic acid oxidation and damage in the colon following stress. Ten rats were stressed by the cold-restraint method; ten were controls. Stress induced $0.5 \pm 0.7$ (S.D.) mucosal erosions whereas controls had none. Subepithelial hemorrhage and erosions occurred only in the proximal two-thirds of the colon. Prostaglandin $E_{2}$ synthesis was increased after stress compared to the control $(381 \pm 130$ vs. $1610 \pm 372 \mathrm{ng} / \mathrm{g} / \mathrm{min})$. Leukotriene $C_{4}$ synthesis also increased after stress $(4217+994$ vs. $11300 \pm$ $1662 \mathrm{ng} / \mathrm{g} / \mathrm{min}$ ). Synthesis of prostaglandin $E_{2}$ increased $(r=0.9381)$ with leukotriene $C_{4}$. The response of the colon to stress is less severe than that in the stomach and may be related to regional regulation of prostaglandin and leukotriene synthesis.

\section{Stress induced experimental colitis}

\author{
T. A. Stein, ${ }^{\text {CA }}$ L. Keegan, L.-J. Auguste, \\ B. Bailey, and L. Wise
}

Department of Surgery, Long Island Jewish Medical Center, The Long Island Campus for the Albert Einstein College of Medicine, 270-05 76th Avenue, New Hyde Park, NY 11042, USA

${ }^{\mathrm{CA}}$ Corresponding Author

Key words: Colitis, Stress, Prostaglandin, Leukotriene

\section{Introduction}

The alimentary tract is very sensitive to stress. The upper gastrointestinal system appears to be more easily damaged by stressful stimuli than the large bowel. The occurrence of peptic ulcers has been linked to stress-induced acid secretion. ${ }^{1}$ Dysfunction of intestinal motility and movement is also stress-related. ${ }^{2}$ In patients with inflammatory bowel disease, emotional stress may slow small bowel movement but increase motility in the colon. $^{3-5}$ Psychological stress may also cause abdominal pain, constipation or diarrhoea, symptoms of irritable bowel syndrome. ${ }^{6,7}$ Dysfunction of the gastrointestinal system is probably caused by alteration in the neurochemical control of motor activity and blood flow. Synthesis and release of neuropeptides and catecholamines in the brain mediate these functions through sympathetic and parasympathetic nerves. The different responses of the proximal and distal gastrointestinal tract to stress may be related in part to the neural control of the synthesis of vasoactive prostaglandins and leukotrienes in these tissues. The effect of stress on these arachidonic acid oxidation products and damage to the colonic mucosa was determined in the present study.

\section{Methods}

Animals: Rats were purchased from Holtzman Co., Madison, WI, and weighed 125-150 g. The rats were housed in an American Association for Laboratory Animal Services approved facility in which humidity and temperature were controlled, and fed Rat Chow (Ralston Purina Co., St Louis, MO). The Guide for the Care and Use of Laboratory Animals was followed as recommended by the Institute of Laboratory Animal Resources National Research Council (Division of Research Resources, Bethesda, MD). Animals adapted to the environment for at least 1 week before being used experimentally. Ten were stressed by the fastingcold-restraint method. ${ }^{8}$ Food was removed for $24 \mathrm{~h}$ before immobilizing the animal under a tight wire screen at $4^{\circ} \mathrm{C}$ for $4 \mathrm{~h}$. Ten control animals remained in their cages undisturbed.

Tissue sampling: Following termination by cervical dislocation, the colon was excised, and the proximal and distal ends were marked. Then the colon was opened along the antimesenteric border. After washing the colons in saline at $4^{\circ} \mathrm{C}$, the serosa was positioned on a glass plate to position the mucosa outward and lesions were identified by one investigator (L.K.) who was blinded to the treatment group. The colon was divided into thirds: proximal, midportion and distal. Lesions with a 2-3 $\mathrm{mm}$ adjacent area and normal appearing tissues from each section were excised for histology. The remaining mucosa was then scraped with the edge of a glass slide, weighed and used for enzyme assay. The stomach was also removed, opened along the lesser curvature and examined for the presence of blood, indicating that stress caused gastric hemorrhage. There was clotted blood in the stomachs from rats which had been stressed, but not in the control group.

Assays: As a measure of the activity of prostaglandin $\mathrm{G} / \mathrm{H}$ synthase and 5-lipoxygenase, $\mathrm{PGE}_{2}$ and $\mathrm{LTC}_{4}$ 
were determined. Approximately $150 \mathrm{mg}$ of tissue was suspended in $1 \mathrm{ml}$ of $0.1 \mathrm{M} \mathrm{NaCl}, 4.8 \mathrm{mM} \mathrm{KCl}$, $1.2 \mathrm{mM} \mathrm{KPO}_{4}, 5 \mathrm{mM}$ glutathione, $1 \mathrm{mM}$ hemin, $3 \mathrm{mM} \quad \mathrm{MgSO}_{4}, 8.8 \mathrm{mM}$ HEPES, and $5 \mathrm{mM}$ poloxamer 188 (a nonionic detergent) at $\mathrm{pH} 8$ to permeabilize the cell membrane for $1 \mathrm{~min}$. The tissue suspension was centrifuged for $1 \mathrm{~min}$ at $1500 \times$ g. The supernatant was decanted and discarded. The tissue was resuspended in $1 \mathrm{ml}$ of the identical buffer containing $132 \mathrm{mM}$ sodium arachidonate, and incubated at $23^{\circ} \mathrm{C}$ for $10 \mathrm{~min}$. The synthesis of prostaglandins and leukotrienes by oxidation of arachidonate was terminated by the addition of $1.5 \mathrm{ml}$ of acetone at $0^{\circ} \mathrm{C}$. Arachidonic acid oxidation products were extracted as previously described. ${ }^{9}$ Prostaglandin $\mathrm{E}_{2}$ and $\mathrm{LTC}_{4}$ were derivatized with panacyl bromide, separated, identified and quantitated by reversed-phase HPLC. $^{10}$

Calculations: The rate of synthesis was calculated in units of $\mathrm{ng} / \mathrm{min} / \mathrm{g}$ wet weight, and the means and standard errors of the mean were determined. Statistical significance between groups was determined by the ANOVA and the relationship between variables was determined by the productmoment correlation.

Histology: Samples of mucosa containing lesions and normal appearing tissues were obtained from stressed rats, and were fixed in a buffered 10\% formaldehyde solution for histology. Mucosa from controls were taken from similar areas of the colon. Specimens were then embedded in paraffin, and $4 \mu \mathrm{m}$ thick sections were cut for placement on a microscope slide. Sections were made at several different levels and stained with hematoxylin and eosin. The occurrence of subepithelial hemorrhage (petechiae), erosions (visible break in the mucosa) and ulcers (penetration of the muscularis mucosae) was determined. ${ }^{11} \mathrm{~A}$ break in the mucosal surface, such as an erosion or ulcer, was more easily quantifiable in the colon than comparing degrees of inflammation, and only the number of breaks were counted.

\section{Results}

Gross and microscopic appearance: The mucosa from control rats was pinkish and had only few erythemic areas. Microscopically, subepithelial hemorrhages occurred only rarely and in two colons, but no erosions were identified (Fig. 1). The surface epithelium was intact, and the crypts of Lieberkükin contained goblet cells. A few lymphocytes were present in the interglandular lamina propria, and lymphatic nodules were well defined.

After cold-restraint stress the gross appearance of the mucosa became paler with an increase in areas

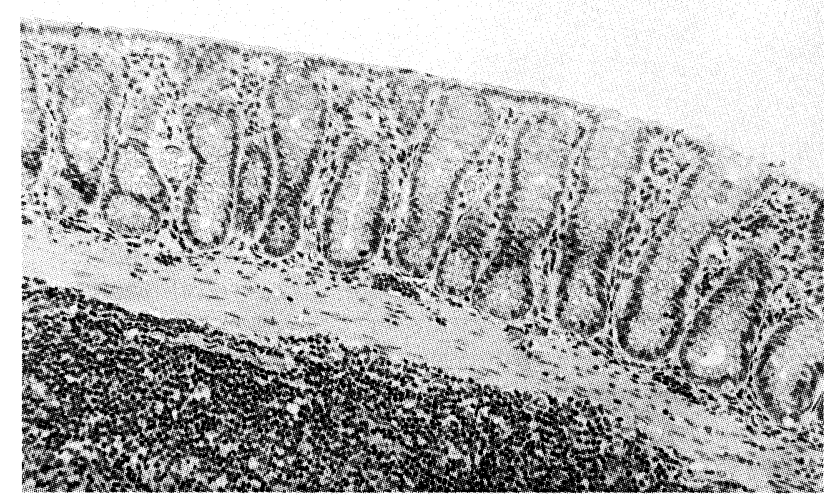

FIG. 1. Colon from control rats which was sampled from the middle third of the bowel. Note the intact surface epithelium and lymph nodule. (Magnification $\times 200, H$ \& E stain)

of erythema. Four colons had well-defined erosions. The mean number of erosions in the stress group was $0.5 \pm 0.7$ (S.E.M.) and occurred only in the proximal two-thirds of the colon (Fig. 2). Subepithelial hemorrhages were occasionally present in the colons and were located near the surface epithelium. The columnar epithelium was lost and erosions extended almost to the base of the crypts but not into the muscularis mucosa (Fig. 3).

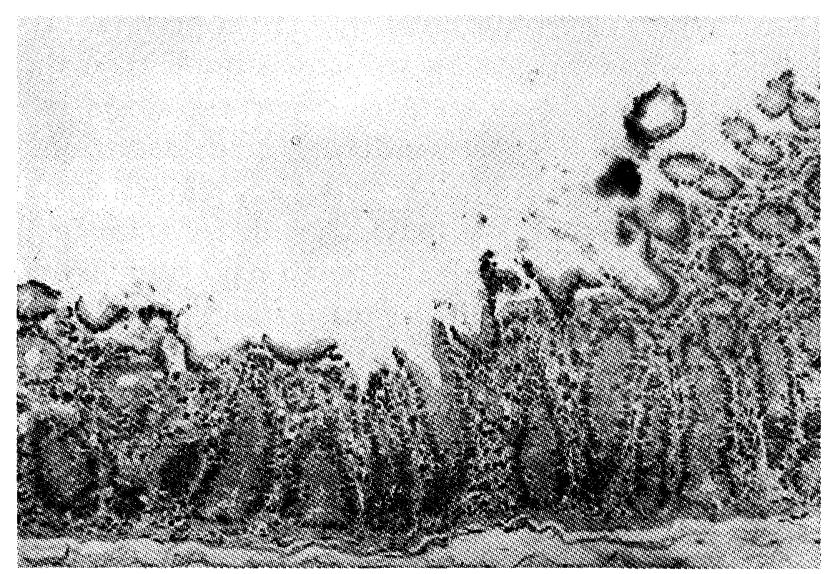

FIG. 2. Inflammation of the mid-colon from a rat stressed for $4 \mathrm{~h}$. Note denuded epithelium, inflammatory cells and hemorrhage in the lamina propria. (Magnification $\times 200, H$ \& E stain)

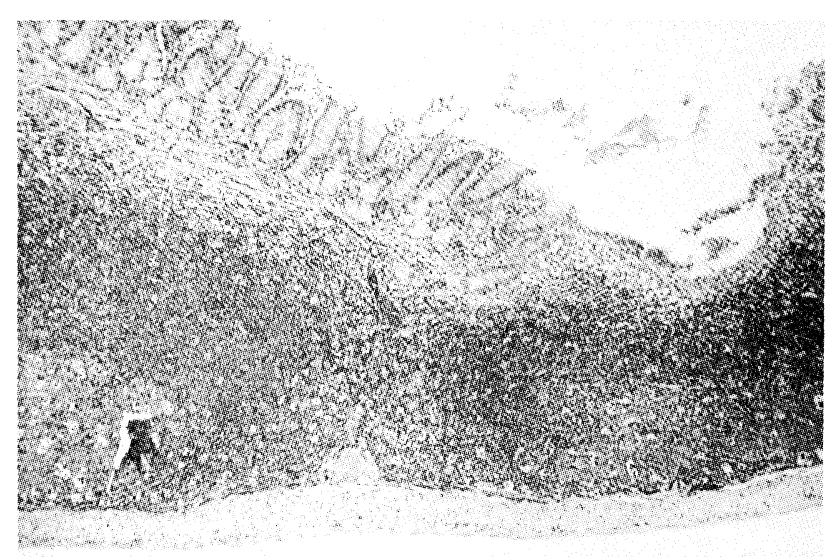

FIG. 3. Ulceration and inflammation of the mid-colon in the rat $4 \mathrm{~h}$ after stress. (Magnification $\times 50, H$ \& E stain) 
Table 1. Effect of stress on arachidonate products

\begin{tabular}{lcc}
\hline Group & Prostaglandin $\mathrm{E}_{2}$ & Leukotriene $\mathrm{C}_{4}$ \\
\hline Control & $381 \pm 130$ & $4217 \pm 994$ \\
Stress & $1610 \pm 372^{*}$ & $11300 \pm 1662^{*}$ \\
\hline
\end{tabular}

Values are in $\mathrm{ng} / \mathrm{g} / \mathrm{min}$ and the mean $\pm \mathrm{S}$.E.M. are shown.

$* p<0.01$, compared to control.

Inflammatory cells were present in the exudate. Lymphatic nodules appeared larger and more lymphocytes were in the interglandular lamina propria than in controls.

Effect of stress on $P G E_{2}$ and $L T G_{4}$ synthesis: Prostaglan$\operatorname{din} E_{2}$ synthesis increased three-fold after stress compared to the control mucosa (Table 1), but there was no relationship between ulceration and prostaglandin $\mathrm{E}_{2}$ synthesis $(r=-0.35667)$. Leukotriene $\mathrm{C}_{4}$ synthesis increased by two-fold in the mucosa after stress, but also had no association with ulceration. A significant correlation $(r=0.93814$, $p<0.001$ ) occurred for the synthesis of prostaglandin $\mathrm{E}_{2}$ and leukotriene $\mathrm{C}_{4}$.

\section{Discussion}

After inducing stress for $4 \mathrm{~h}$, all stomachs were hemorrhagic and had many lesions, but only a few colons had erosions. Although erythema and subepithelial hemorrhage was not scored or given a subjective number, the gross appearance of the mucosa suggested that cold-restraint stress induces colitis in many rats. Psychological stress could be responsible for the mild symptoms of gastrointestinal dysfunction experienced by healthy individuals.

In the normal colon, arachidonate appears to be primarily oxidized via the lipoxygenase rather than by the prostaglandin $\mathrm{G} / \mathrm{H}$ synthase pathway. In the stomach, prostaglandin synthase is the major pathway, since leukotriene synthesis is approximately half of prostaglandin synthesis. ${ }^{12}$ Stress induces an increase in leukotriene synthesis in the stomach which, compared to $\mathrm{PGE}_{2}$, indicates that arachidonate oxidation changed toward leukotriene production. The normal colon appears to have a greater capacity for leukotriene synthesis than the stomach. While stress induces a significant increase in leukotriene synthesis in the stomach, there is only a two-fold increase in the colon. Comparing the relative synthesis of leukotriene and prostaglandin, there is no change in the direction of arachidonate oxidation after stress in the colon. The positive correlation of prostaglandin and leukotriene synthesis indicates that a common substrate to both enzymes must be limiting synthesis. Since specimens are incubated in an excess of arachidonate for assay, the amount of oxygen available in tissue for synthesis is probably limiting oxidation. The lack of a significant correlation of erosions and synthesis of prostaglandins and leukotrienes is due to the small number of lesions.

The stress-related decrease in $\mathrm{PGE}_{2}$ synthesis which occurs in gastric mucosa appears to be related to inadequate levels of arachidonic acid and oxygen. ${ }^{12-14}$ Corticosteroids inhibit phospholipase $\mathrm{A}_{2}$ activity and the release of arachidonic acid from membrane phospholipids. ${ }^{15,16}$ Decreased blood flow would also diminish the delivery of extracolonic fatty acids to the mucosa for prostaglandin synthesis. The activity of prostaglandin synthase activity in the gastric mucosa is not impaired during stress if adequate levels of arachidonic acid are present. ${ }^{12}$ Lipoxygenase activity, however, increases significantly with stress, and the shunting of arachidonic acid from prostaglandin synthesis to leukotriene synthesis is correlated with gastric erosions. ${ }^{12}$ The colon sustains less injury after stress but both enzyme activities are increased. No shunting of arachidonic acid from $\mathrm{PGE}_{2}$ to leukotrienes is apparent in the colon. The greater capacity of the colon for PGE $\mathrm{PG}_{2}$ and $\mathrm{LTC}_{4}$ synthesis suggests that blood flow and mucosal oxygenation was adequate during stress.

Intracellular arachidonate levels, however, may be limited in the colonic mucosa, affecting the synthesis of $\mathrm{PGE}_{2}$ and $\mathrm{LTC}_{4}$, decreasing blood flow and inducing ulceration in some animals.

Some evidence supporting a role for prostaglandin as mediators of cytoprotection in the colonic mucosa exists. Exogenous $\mathrm{PGE}_{2}$ administration reduces damage to the mucosa of the colon induced by bile salts or ethanol. ${ }^{17,18}$ Prostaglandin $E_{2}$ prevents also gastric mucosal ulceration in a variety of stress models and its synthesis is important in cytoprotection against injurious agents. ${ }^{19,20}$ The increased synthesis of $\mathrm{PGE}_{2}$ seen in inflammatory bowel disease may be related to a protective feedback mechanism once an insult to the mucosa occurs.

Subepithelial hemorrhage and lesions in the proximal colon and increased synthesis of $\mathrm{PGE}_{2}$ and $\mathrm{LTC}_{4}$ after stress may be related to its innervation. The distal colon, which had no visual damage after stress, receives parasympathetic neural fibers via pelvic nerves rather than the vagus nerve. Neurochemicals act with specificity and selectivity at different sites in the brain stem. Corticotropinreleasing factor (CRF) inhibits gastric acid secretion, gastric emptying and small bowel movement but stimulates colonic movement and faecal excretion. ${ }^{21,22}$ Subdiaphragmatic vagotomy prevents the delay in gastric emptying but has no effect on colonic movement. ${ }^{22}$ The central nucleus of the 
amygdala may be particularly sensitive to neurotensin, $\beta$-endorphines and thyrotropin-releasing hormone and probably integrates stress-related inputs to connect the cortex with the hypothalamus and lower brain stem. ${ }^{23}$ Neurotensin increases $\mathrm{PGE}_{2}$ synthesis through an $\alpha$-adrenergic mechanism which decreases acid secretion and increases mucosal blood flow. ${ }^{24}$ Differences in response of the colon and stomach to stressful stimuli are probably related, in part, to the neural control of prostaglandin and leukotriene synthesis in these tissues.

\section{References}

1. Richardson CT. Pathogenic factors in peptic ulcer disease. Am J Med 1985; 79 (Suppl 12C): $1-7$

2. Williams CL, Villar RG, Peterson JM, Burks TF. Stress-induced changes in intestinal transit in the rat: a model for irritable bowel syndrome. Gastroenterology 1988; 94: 611-621.

3. Cann PA, Read NW, Cammack J. Psychological stress and the passage of a standard meal through the stomach and small intestine in man. Gut 1983; 24: 236-240.

4. Latimer P, Sarna S, Campbell D, et al. Colonic motor and myoelectric activity: a comparative study of normal subjects, psychoneurotic patients, and patients with IBS. Gastroenterology 1981; 80: 893-901.

5. Narducci F, Snape WJ, Battle WM, London RL, Cohen S. Increased colonic motility during exposure to a stressful situation. Dig Dis Sci 1985; 30:40-44.

6. Whitehead WE, Engel BT, Schuster MM. Irritable bowel syndrome: physiological and psychological differences between diarrhoea-predominant and constipation-predominant patients. Dig Dis $S_{c i}$ 1980; 25: 404-413.

7. Sarna SK. Physiology and pathophysiology of colonic motor activity. Dig Dis Sci 1991; 36: 998-1018.

8. Auguste LJ, Kassan MA, Stone AM, et al. Prostaglandin mediation of the effect of vagotomy in the prevention of stress ulceration. Einstein Quart Biol Med 1991; 9: 99-101.

9. Stein TA, Angus L, Borrero E, Auguste L, Wise L. Picogram measurement of prostaglandin $\mathrm{E}_{2}$ synthesis by gastric mucosa by high-performance liquid chromatography. J Chromatogr 1987; 385: 377-382.
10. Stein TA, Bailey B, Auguste LJ, Wise L. Measurement of prostaglandin $\mathrm{G} / \mathrm{H}$ synthase and lipoxygenase activity in the stomach wall by HPLC BioTechniques 1991; 10: 222-225.

11. Laine L, Weinstein WM. Subepithelial hemorrhages and erosions of human stomach. Dig Dis Sci 1988; 33: 490-503.

12. Stein TA, Keegan L, Auguste LJ, Bailey B, Wise L. Stress-induced gastric lesions and the synthesis of prostaglandins and leukotrienes. J Surg Res 1991; 51: $368-371$.

13. Auguste LJ, Angus L, Stein TA, Wise L. Arachidonic acid protection of rat mucosa against stress-ulceration. J Surg Res 1987; 43: 103-106.

14. Auguste LJ, Lackner R, Ratner L, Stein TA, Bailey B. Prevention of stres induced erosive gastritis by parenteral administration of arachidonic acid. JPEN 1990; 14: 615-617.

15. Flower RJ, Blackwell GJ. Anti-inflammatory steroids induce biosynthesis of a phospholipase $\mathrm{A}_{2}$ inhibitor which prevents prostaglandin generation. Nature (Lond) 1979; 278: 456-459.

16. Frame MH, Main IHM. Effects of arachidonic acid on rat gastric secretion in response to different secretagogues; inhibition of these effects by indomethacin. Br J Pharmacol 1980; 69: 171-178.

17. Wallace JL, Whittle BJR, Broughton-Smith NK. Prostaglandin protection of rat colonic mucosa from damage induced by ethanol. Dig Dis Sci 1988 30: 866-876.

18. Argenzio RA, Henrikson CK, Liacos JA. Effect of prostaglandin inhibitor on bile salt-induced mucosal damage of porcine colon. Gastroenterology 1989 96: 95-109.

19. Yoshimura H, Kan N, Ogawa N. Preventive and curative effects of prostaglandins on stress ulcer in rats. Dig Dis $S_{c i}$ 1989; 34: 436-444.

20. Victor BE, Schmidt KL, Smith GS, et al. Prostaglandin-induced gastric mucosal protection against stress injury. Ann Surg 1989; 209: 289-296.

21. Hernandez DE, Jennes C, Emerick SG. Brain vasoactive peptide: A potent stimulant of gastric acid secretion. Brain Res 1987; 420: 129-134.

22. Burks TF. Central nervous system regulation of gastrointestinal motility Ann NY Acad Sci 1990; 597: 36-42.

23. Hernandez DE. The role of brain peptides in the pathogenesis of experimental stress gastric ulcers. Ann NY Acad Sci 1990; 597: 28-35.

24. Kauffman GL, Zhang L, Xing L, et al. Central neurotensin protects the mucosa by a prostaglandin-mediated mechanism and inhibits gastric acid secretion in the rat. Ann NY Acad Sci 1990; 597: 175-190.

\section{Received 8 March 1993}

accepted in revised form 8 April 1993 


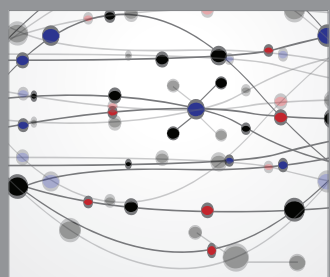

The Scientific World Journal
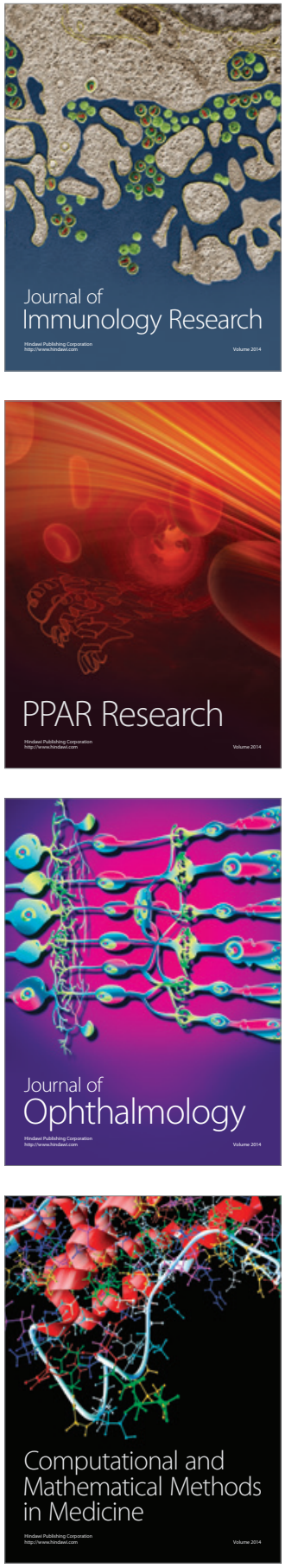

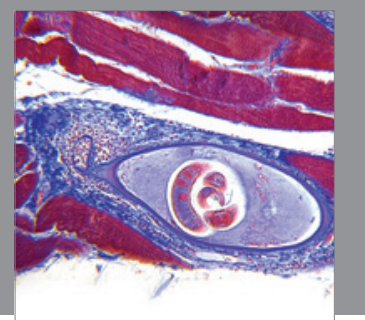

Gastroenterology

Research and Practice
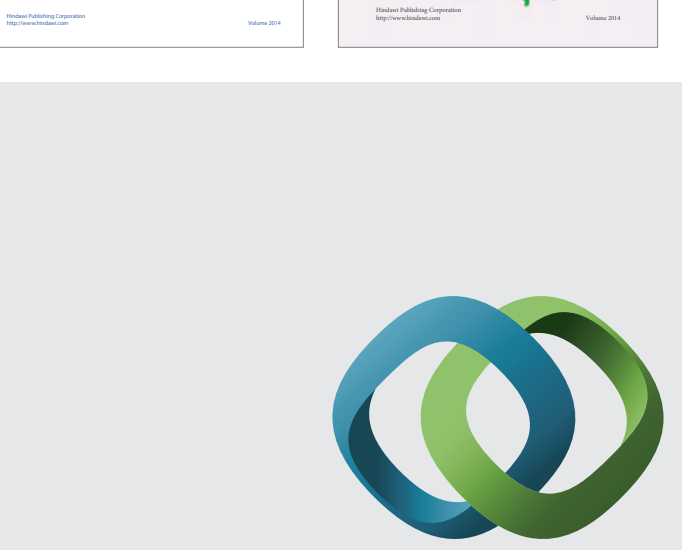

\section{Hindawi}

Submit your manuscripts at

http://www.hindawi.com
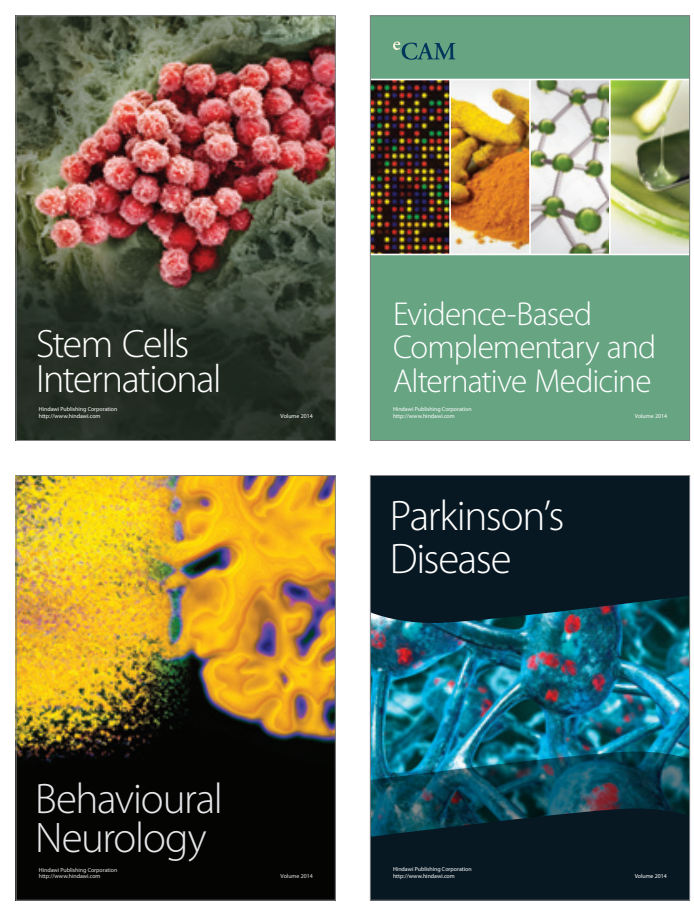

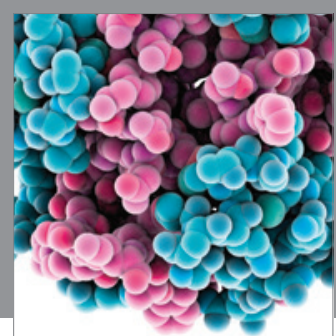

Journal of
Diabetes Research

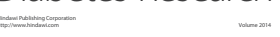

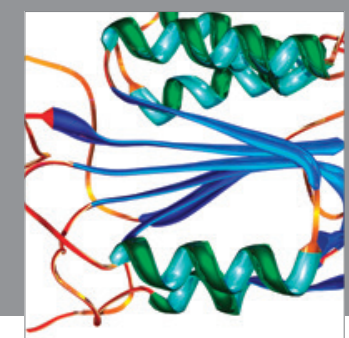

Disease Markers
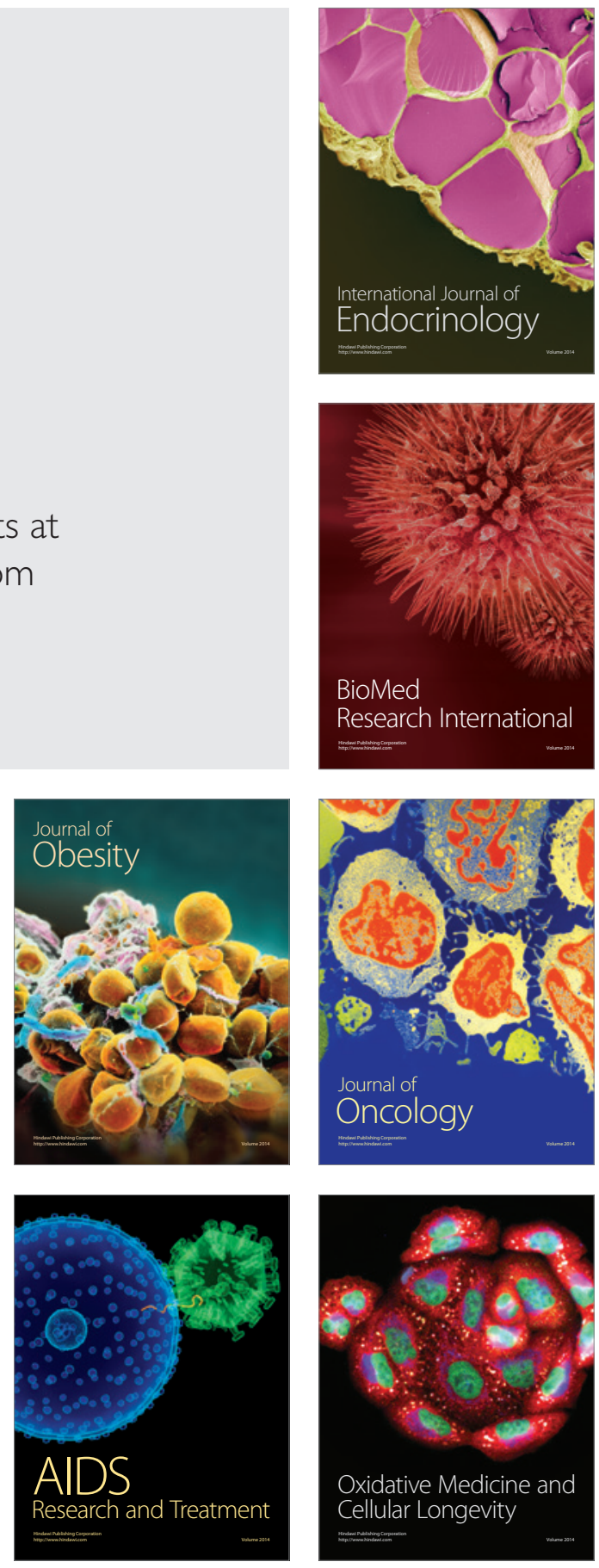